\title{
Protein redox chemistry: post-translational cysteine modifications that regulate signal transduction and drug pharmacology
}

\author{
Revati Wani ${ }^{1}$, Asako Nagata ${ }^{2}$ and Brion W. Murray ${ }^{1}$ * \\ 1 Oncology Research Unit, Pfizer Worldwide Research and Development, San Diego, CA, USA \\ ${ }^{2}$ Worldwide Medicinal Chemistry, Pfizer Worldwide Research and Development, San Diego, CA, USA
}

Edited by:

Maurizio Bifulco, University of

Salerno, Italy

Reviewed by:

Rayudu Gopalakrishna, University of Southern California, USA

Simona Pisanti, University of Salerno, Italy

\section{${ }^{*}$ Correspondence:}

Brion W. Murray, Oncology Research Unit, Pfizer Worldwide Research and Development, 10646 Science Center Drive, San Diego, CA 92121, USA e-mail: brion.murray@pfizer.com
The perception of reactive oxygen species has evolved over the past decade from agents of cellular damage to secondary messengers which modify signaling proteins in physiology and the disease state (e.g., cancer). New protein targets of specific oxidation are rapidly being identified. One emerging class of redox modification occurs to the thiol side chain of cysteine residues which can produce multiple chemically distinct alterations to the protein (e.g., sulfenic/sulfinic/sulfonic acid, disulfides). These post-translational modifications (PTM) are shown to affect the protein structure and function. Because redox-sensitive proteins can traffic between subcellular compartments that have different redox environments, cysteine oxidation enables a spatio-temporal control to signaling. Understanding ramifications of these oxidative modifications to the functions of signaling proteins is crucial for understanding cellular regulation as well as for informed-drug discovery process. The effects of EGFR oxidation of $\mathrm{CyS}_{797}$ on inhibitor pharmacology are presented to illustrate the principle. Taken together, cysteine redox PTM can impact both cell biology and drug pharmacology.

Keywords: ROS, redox, cysteine oxidation, kinase, EGFR, subcellular trafficking, covalent drugs

\section{INTRODUCTION}

Reactive oxygen species (ROS) are the product of tightly controlled metabolic and cellular processes including mitochondrial respiration, cytokine and mitogen stimulations. They are also produced in response to external stressors such as pathogens, chemicals, and radiation (Bae et al., 1997; Dickinson and Chang, 2011; Bindoli and Rigobello, 2013). The ROS family broadly encompasses free radical (e.g., superoxide, $\cdot \mathrm{O}_{2}^{-}$; hydroxyl, $\cdot \mathrm{OH}$ ) and non-radical (e.g., peroxides) species (Cross and Templeton, 2006; Jacob et al., 2011). Superoxides and hydrogen peroxide are kinetically favorable for modifying select cysteine residues due to their regulated production (enzymatic, non-enzymatic), different rates of formation, half-lives and inherent reactivities relative to the more "toxic" hydroxyl radical (D'Autreaux and Toledano, 2007; Winterbourn, 2008; Drose and Brandt, 2012; Marinho et al., 2014). The key determinants of whether ROS function as secondary messengers for signal transduction or agents of cellular damage reside in the amount, type and cellular location of reactive species produced in response to its molecular trigger. Commonly understood aspects of redox modifications from ROS exposure include changes to the structure and conformation of proteins as well as inactivation of catalytic residues. However, the ability of specific oxidation reactions with ROS to alter interactions with small molecule inhibitors is poorly understood. The goal of this Perspective is to illuminate the complex interplay of localized production of ROS, protein oxidation events and drug interactions.
THE CHEMISTRY OF CYSTEINE BIOLOGY: WHY CELLS PREFER CYSTEINE FOR OXIDATION?

The knowledge of sulfur chemistry is central to understanding how and why cysteine residues get preferentially oxidized during biological regulation. There are two sulfur-containing residues in the mammalian proteome, cysteine and methionine, of which cysteine constitutes 1-2\% (Miseta and Csutora, 2000). The facile chemistry of cysteine stems from the electronic structure of its thiol group which enables multiple oxidation states (from -2 to +6) leading to an array of redox modifications (sulfenylation, $\mathrm{SOH}$; sulfinylation, $\mathrm{SO}_{2} \mathrm{H}$; sulfinylation, $\mathrm{SO}_{3} \mathrm{H}$; glutathionylation, -SSG; protein disulfide formation; nitrosylation, etc.) with distinct chemical properties that contribute to signaling specificity (Wang et al., 2012). For instance, oxidation of the relatively hydrophobic cysteine residue to an oxoacid form (e.g., sulfinic acid) fundamentally changes it to a highly polar residue. Also, many types of cysteine oxidative modifications are readily reversible making them well-suited for initiating, amplifying, and terminating redox signaling relative to other residues (Bindoli et al., 2008). As such, this malleable chemistry confers unique capabilities to cysteine residues for sensing and transducing signaling by modifying the structure and function of proteins.

Oxidation of methionine, the other sulfur-containing amino acid, also leads to similar chemotypes as cysteine, however; the slower rate of methionine oxidation combined with rapid reduction by methionine sulfoxide reductase (MSR) minimizes its role in signaling regulation and suggests a role as redox scavengers (D'Autreaux and Toledano, 2007). Furthermore, 
reduced MSR expression in cells, aging individuals, and Alzheimer subjects is correlated with increased methionine oxidation which is consistent with an antioxidant function (Moskovitz, 2005; Schoneich, 2005; Moskovitz et al., 2011; Ringman et al., 2012). However, a recent study infers a role of methionine oxidation in signaling due to its proximity to Ser/Thr/Tyr residues which could impact phosphorylation networks (Rao etal., 2013). Further research on this intriguing correlation is necessary to establish the role of methionine oxidation as a signaling regulator. In addition to the sulfur-containing amino acids, oxidation of other amino acid residues can occur but they are not readily reversible making them ill-suited for initiating rapid on/off responses to upstream signals (Dickinson and Chang, 2011; Corcoran and Cotter, 2013). Cysteine oxidative modifications are therefore preferred for modulating signal transduction since they readily react with most ROS (Schoneich, 2011) to create a range of modifications that are largely reversible.

With an increased array of selective probes that label different redox chemotypes, our knowledge of proteins modified by oxidation is growing rapidly. Some of the known redox-modified kinases include MKK4 (Diao et al., 2010), PKC (protein kinase C) (Gopalakrishna and Jaken, 2000; Korichneva, 2005), Src (sarcoma kinase) (Giannoni etal., 2005), Akt2 (Wani etal., 2011), and more recently EGFR (epidermal growth factor receptor) (Paulsen etal., 2012; Schwartz etal., 2014). These modifications can be activating (PKC, Src, EGFR) or inhibitory (MKK4, AKT2). Redox-inactivation of phosphatases such as PTP1B, PTEN, and PP2A is also wellcharacterized (Kwon etal., 2004; Foley etal., 2007; Östman et al., 2011; Kitagishi and Matsuda, 2013). Other protein classes are also oxidatively modified including transcription factors (Surh etal., 2005; Cross and Templeton, 2006), ion channels; mitochondrial transporter proteins (O-Uchi et al., 2014), and cytoskeletal proteins (Landino etal., 2007; Farah etal., 2011). Therefore, selective oxidation of cysteine residues are posttranslational modifications (PTM) with unique properties and capabilities.

\section{COMPARTMENTALIZED SIGNALING CONTRIBUTES TO SPECIFICITY OF REDOX REGULATION}

Ligand stimulation of receptor tyrosine kinases (RTK) causes the translocation of the ligand - RTK complexes to clathrincoated pits on the plasma membrane which bud off as endosomes and internalize (Carpenter and Liao, 2009; Murphy et al., 2009). From the endosome, RTK's can traffick to lysosomes for degradation, to other intracellular destinations (e.g., cytoplasm, nucleus, mitochondria), or back to the membrane (recycling). EGFR endocytosis is a fairly well-understood process which also enables signaling from the endosome itself. (Paige Davis Volk and Moreland, 2014). Depending on the type of ligand (e.g., EGF, TGF $\alpha$ ) and its dimerization partner, EGFR trafficking can either terminate in the lysosomes (following EGFRubiquitination) or at the membrane (recycling; Murphy et al., 2009; Sorkin and Goh, 2009). The mechanism of spatial regulation of EGFR signaling can be inferred from empirical studies that demonstrate how endoplasmic reticulum (ER)-based NOX4 produces ROS to locally inactivate the phosphatase PTP1B which allows the active receptor (phosphorylated EGFR) to recycle back to the membrane (Chen etal., 2008; Tomas et al., 2014). This diffusion-restricted process promotes spatial RTK signaling by (1) localizing ROS within the endosomal compartment and (2) preventing plasma membrane and cytoplasmic regulators (e.g., glutathione, antioxidant enzymes, trace metals) from interacting with the endosomal ROS. As such, the endosomal environment alters the local half-life of select ROS species to impart signaling selectivity.

Different oxidative modifications of the same protein, but at distinct subcellular locations, can add another layer of complexity to redox regulation. For example, recent biochemical studies on the reactivation of peroxide-inactivated PTP1B find different rates of recovery of its activity based on the reduction mechanism - enzymatic (thioredoxin, Trx) or by a non-protein thiol (glutathione, GSH). This study indicated that Trx selectively reduces lower order redox forms (sulfenic acid and sulfenyl amide) of PTP1B compared to GSH, which could also reduce some higher oxidized forms or sulfinyl derivatives of PTP1B. Interestingly, under comparable conditions Trx restored catalytic activity of PTP1B more efficiently than GSH (Parsons and Gates, 2013). If we extend this concept to cellular settings and assume that a fraction of PTP1B is localized within an endosome, then the stabilization of its sulfenyl form relative to the sulfinyl fraction would be largely determined by the dominant reducing agent in an endosome (Trx vs. GSH). Integrating this process with EGFR endocytosis suggests that the recycling rate of PTP1B would directly regulate the lifetime of active EGFR and therefore the amplitude of endosomal EGFR signaling. Also, the differential stability of individual sulfenylated/sulfinylated/disulfide-linked fractions of the EGFR molecules within endosomes can contribute to its signaling regulation.

Cysteine reactivity can be context-specific because the acid dissociation constant $\left(\mathrm{p} K_{\mathrm{a}}\right)$ of a cysteine residue's thiol varies widely in proteins $\left(\mathrm{p} K_{\mathrm{a}} 3-9\right)$ depending on many factors (Cremers and Jakob, 2013). As redox-sensitive proteins travel between different cellular compartments they are subjected to rapid changes in local $\mathrm{pH}$, redox environment (vicinal protein/non-protein thiols, proximity to metal centers and positively charged residues) and solvent access that collectively affect the $\mathrm{p} K_{\mathrm{a}}$ of their critical cysteine(s) (Roos et al., 2013). Thus, the local microenvironment affects protein thiol nucleophilicity which promotes spatially distinct, redox-mediated signaling. In addition, the different intrinsic rates of formation, diffusibility and stability of ROS (Bindoli et al., 2008) in these subcellular compartments adds a temporal control to redox regulation.

Post-translational modifications other than oxidation (e.g., phosphorylation, glycosylation, ubiquitination) can combine with redox regulation to impact cellular functions. For example, recent studies indicate that sodium arsenite-mediated oxidative stress promotes nuclear expulsion of the transcription factor Nurr1; a protein involved in survival of dopaminergic neurons with possible implications in neurodegenerative disorders such as Parkinson (García-Yagüe et al., 2013). As Erk1/2 phosphorylates Nurr1 (Lu et al., 2012), there is a possibility for combined phosphorylation and redox regulation in the nuclear/cytoplasmic trafficking of 
Nurr1. In case of EGFR, hydrogen peroxide treatment in cells is known to induce both EGFR phosphorylation and oxidation at Cys797 (sulfenylation; Paulsen et al., 2012) which independently enhance its catalytic activity. Hydrogen peroxide treatment of cells also enables trafficking of active EGFR to the perinuclear region by selective endocytosis (caveolar) and blocks ubiquitin-mediated degradation resulting in prolonged EGFR signaling (Khan et al., 2006; Sorkin and Goh, 2009). The narrow time window between peroxide-driven oxidation and phosphorylation could play a role in regulating membrane-based versus endosomal EGFR signaling. Therefore, resolving the time courses of individual PTMs can be crucial to understanding the functional responses of signaling proteins. Taken together, dynamic variations in the redox environment, nucleophilicity of the cysteine thiol, and the interplay with other PTMs during trafficking collectively determines the stability of a select protein oxidation event in a subcellular compartment thus resolving the kinetics of spatio-temporal signaling.

\section{DOES OXIDATION MODULATE PROTEIN CONFORMATION?}

The structure and conformation of proteins are central to their biological function. Redox regulation of protein conformation can be achieved by multiple mechanisms (1) cysteine oxidation leading to disulfide bond formation, (2) cysteine-dependent metal cofactor interactions, and (3) cysteine modifications that alter the topography of a protein (e.g., sulfinic acid, sulfenamide). Disulfide bond formation is a well-established mechanism stabilizing higher order protein structures occurring in the oxidizing environment of ER during protein maturation (Zhong and Wright, 2013). These structural disulfide bonds are characterized by very low redox potentials (as low as $-470 \mathrm{mV}$; Fan et al., 2009; Wouters et al., 2010) and will not be addressed in this Perspective. Another category of disulfide bond has emerged more recently, redox-active disulfide bonds, which are energetically distinct from structural disulfides (redox potential from -95 to $-330 \mathrm{mV}$ ) and are used in dynamic regulatory mechanisms (Fan et al., 2009; Wouters et al., 2010). For example, integrins require reduced cysteine residues to achieve an active conformation and are inactivated upon disulfide bond formation (Yan and Smith, 2000, 2001; Chigaev et al., 2004). DTT-induced reduction (in vitro) of the candidate disulfide bonds (Cys $\left.406 / \mathrm{Cys}_{655}, \mathrm{Cys}_{457} / \mathrm{Cys}_{495}\right)$ and disulfide rearrangements of other cysteine residues drives the integrin conformation to its active state. This mechanism of integrin activation has been targeted by a small molecule agent to re-sensitize drug-resistant acute myelogenous leukemia cells to chemotherapy (Layani-Bazar et al., 2014). Another biological relevant catagory of disulfide bond is mixed disulfides (e.g., glutathionylation). Actin glutathionylation studies illustrate the functional significance of this type of modification. Ischemia-reperfusion induces glutathionylation of actin at $\mathrm{Cys}_{374}$ which blocks polymerization of $\alpha$-actin filaments, decreases actomyosin ATPase activity (Pizarro and Ogut, 2009), and reduces muscle contractility. An array of sarcomeric proteins are additionally shown to be oxidized, (e.g., troponin, tropomyosin) suggesting that cardiac contractility is regulated by a network of redox-modified proteins (Steinberg, 2013).

The well-studied mechanism of redox-induced conformational change involves metal-derived redox reactions that occur frequently with changes in cellular thiol balance (Ilbert et al., 2006;
Fan etal., 2009). Conformational changes resulting from $\mathrm{Zn}$ release in proteins such as Hsp33 (Ilbert et al., 2006), metallothionein (Oteiza, 2012), thioredoxin 2 from Escherichia coli (El Hajjaji et al., 2009), PKC (Zhao et al., 2011), and antisigma factor RsrA (Heo et al., 2013) routinely occur following oxidative stress. The coordinating cysteine residues in the zinc finger cluster form intramolecular disulfides releasing $\mathrm{Zn}$ which leads to unfolding of the redox-responsive region in Hsp33. This exposes both the dimerization interface and substrate binding site to enhance folding of the target proteins and alternatively prevents their aggregation until the cellular stress (e.g., redox, temperature) is relieved (Ilbert et al., 2006). Kinetic studies measuring reactivities of zinc finger peptides with peroxide and oxygen suggest that binding of $\mathrm{Zn}$ to the reduced Hsp33 monomers minimizes the nucleophilicity or thiolate form (S-) of the coordinating cysteine residues and curbs redox reactions (Bourles et al., 2011). Another example is the zinc metalloprotein metallothionein which is redox-regulated to affect zinc transfer and homeostasis (Oteiza, 2012).

Specific redox modifications of cysteine residues can change their chemical properties, alter protein topography, and contribute to biological regulation. For example, oxidation of PTP-1B catalytic cysteine $\left(\mathrm{Cys}_{215}\right)$ to sulfenamide via a sulfenic acid intermediate induces major structural rearrangements of two loops in its active site and is shown to be essential for substrate recognition and catalysis (Brandes et al., 2009). Taken together, redox-regulated conformational changes in signaling proteins occur by an array of mechanisms and play important roles in biological regulation.

\section{ONCOLOGY TARGETS OF REDOX: KINASES WITH A HINGE REGION CYSTEINE IN THEIR CATALYTIC DOMAIN}

One of the best known non-catalytic cysteine nucleophiles occurs in the catalytic domain of a group of 11 protein kinases that includes EGFR. A brief overview of the known pathophysiological roles of these kinases along with a list of investigational and approved drugs from the most recent literature is included (Table 1). In physiological conditions, EGF ligand stimulation induces receptor dimerization followed by autophosphorylation of activation loop tyrosine residues, recruitment of the adaptor proteins, and activation of downstream signaling pathways to regulate fundamental cellular processes. In the disease setting, EGFR can be up-regulated, mutated, and constitutively activated in a range of solid tumors and leukemias. (Seshacharyulu et al., 2012; Sasaki etal., 2013; Arteaga and Engelman, 2014). Phylogenetic analysis of the six cysteine residues distributed throughout the EGFR catalytic domain demonstrates a strong evolutionary conservation (Figures 1A,C). Although zebrafish share only about $40 \%$ sequence identity with human EGFR, the catalytic domain cysteines remain conserved which suggests a strong biological relevance of these residues. Of the six residues, four ( $\mathrm{Cys}_{781}, \mathrm{Cys}_{818}$, Cys939, and Cys950) possess limited solvent access. Two of these four cysteines are deeply buried in the hydrophobic pocket while the other two are at the surface but their side chains point inward thus restricting solvent access. The remaining two residues (Cys797, Cys 775 ) are in close proximity to solvent channels (Figure 1B) and 
Table 1 | Protein kinases with a nucleophilic cysteine residue in the hinge region of the catalytic domain.

\begin{tabular}{|c|c|c|c|}
\hline Kinase & Biological function & Disease relevance & $\begin{array}{l}\text { Approved and investigational } \\
\text { drugs }\end{array}$ \\
\hline EGFR & $\begin{array}{l}\text { Proliferation, development and differentiation of } \\
\text { squamous epithelial cells, regulates cell cycle, } \\
\text { cytoskeletal reorganization, and cell migration }\end{array}$ & $\begin{array}{l}\text { NSCLC, colorectal cancer, breast cancer, } \\
\text { cervical cancer, prostate cancer, renal cell } \\
\text { carcinoma, bladder cancer, head, and neck } \\
\text { cancer }\end{array}$ & $\begin{array}{l}\text { Dacomitinib; Afatinib; Iressa } \\
\text { (Gefitinib); Tarceva (Erlotinib); } \\
\text { Erbitux (Cetuximab); Tykerb } \\
\text { (Lapatinib); Vectibix (Panitumumab); } \\
\text { Caprelsa (Vandetanib); AZD9291; } \\
\text { CO-1686 }\end{array}$ \\
\hline HER2/ErbB2 & $\begin{array}{l}\text { Regulates proliferation, differentiation, and } \\
\text { cytoskeletal rearrangement in cells, regulates } \\
\text { transcription and cell cycle, and cell migration }\end{array}$ & $\begin{array}{l}\text { Breast cancer, glioma, ovarian cancer, lung } \\
\text { cancer, hereditary diffuse gastric cancer }\end{array}$ & $\begin{array}{l}\text { Dacomitinib; Afatinib; Herceptin } \\
\text { (Trastuzumab); Kadcyla } \\
\text { (ado-trastuzumab emtansine); } \\
\text { Perjeta (Pertuzumab); Tykerb } \\
\text { (Lapatinib) }\end{array}$ \\
\hline HER4/ErbB4 & $\begin{array}{l}\text { Proliferation, development, and differentiation of } \\
\text { cardiomyocytes; migration of neural crest cells } \\
\text { and mammary epithelial cells }\end{array}$ & $\begin{array}{l}\text { Schizophrenia, breast cancer (tumor } \\
\text { suppressor), medulloblastoma, viral leukemia }\end{array}$ & Dacomitinib; Tykerb (Lapatinib) \\
\hline BTK & $\begin{array}{l}\text { Development, proliferation, and activation of } \\
\text { myeloid cells, mast cells and B-cells; regulation } \\
\text { of apoptotic signaling; transcriptional regulation } \\
\text { of NF-kB }\end{array}$ & $\begin{array}{l}\text { X-linked agammaglobulinemia, multiple } \\
\text { myeloma, non-hodgkin lymphoma, } \\
\text { immunodeficiency, wiskott-aldrich syndrome, }\end{array}$ & $\begin{array}{l}\text { Ibrutinib (PCI-32765) } \\
\text { GDC-0834; CGI-560; HM-71224; } \\
\text { CC-292; ONO-4059; CNX-774; } \\
\text { LFM-A13 }\end{array}$ \\
\hline ITK & $\begin{array}{l}\text { Regulates T-cell signaling, trafficking, } \\
\text { proliferation, and viral replication }\end{array}$ & $\begin{array}{l}\text { Inflammatory skin diseases such as atopic } \\
\text { dermatitis, psoriasis, allergic contact dermatitis }\end{array}$ & Ibrutinib (PCl-32765) \\
\hline$B M X$ & $\begin{array}{l}\text { Cell differentiation, inflammatory signaling, } \\
\text { motility, survival, and angiogenesis }\end{array}$ & $\begin{array}{l}\text { Hepatocellular carcinoma, prostatic } \\
\text { intraepithelial neoplasia, ischemia, leukemia, } \\
\text { lung cancer, arthritis }\end{array}$ & $\begin{array}{l}\text { Ibrutinib (PCl-32765); MK2206; } \\
\text { Canertinib (Cl-1033) }\end{array}$ \\
\hline BLK & $\begin{array}{l}\text { Regulates B cell development, differentiation } \\
\text { and activation; modulates beta cell function in } \\
\text { pancreatic islets }\end{array}$ & $\begin{array}{l}\text { Maturity-onset diabetes of the young } 11 \\
\text { (MODY-11), motor neuropathy, scleroderma, } \\
\text { arthritis, lupus, acute lymphoblastic leukemia }\end{array}$ & None to date \\
\hline TXK & $\begin{array}{l}\text { Growth, development, differentiation and } \\
\text { activation of T Iymphocytes; actin reorganization; } \\
\text { regulates cytokine production in TH1 cells }\end{array}$ & $\begin{array}{l}\text { Rheumatoid arthritis, Behcet's disease, } \\
\text { bronchial asthma, atopic dermatitis }\end{array}$ & Ibrutinib (PCl-32765) \\
\hline TEC & $\begin{array}{l}\text { T cell development, differentiation and cytokine } \\
\text { production (IL2); regulates growth and } \\
\text { differentiation of myeloid cells }\end{array}$ & $\begin{array}{l}\text { X-linked agammaglobulinemia, autoimmune } \\
\text { conditions, inflammatory diseases, arthritis, } \\
\text { congenital fibrosarcoma, hepatitis, squamous } \\
\text { cell carcinoma, lymphedema }\end{array}$ & Ibrutinib (PCl-32765) \\
\hline JAK3 & $\begin{array}{l}\text { Cell growth, development and differentiation; } \\
\text { regulates hematopoiesis and gene expression } \\
\text { via STAT signaling }\end{array}$ & $\begin{array}{l}\text { Psoriasis, rheumatoid arthritis, severe } \\
\text { combined immunodeficiency (autosomal } \\
\text { recessive for } \mathrm{T}^{-} \text {cell -ve/B cell +ve/NK cell -ve) }\end{array}$ & Tofacitinib, VX-509 \\
\hline MKK7 & $\begin{array}{l}\text { Activated in response to cellular stresses, } \\
\text { proinflammatory cytokines and regulates } \\
\text { apoptotic signaling in neurons. Activates } \\
\text { SAPK/JNK pathways in cells, regulates toll-like } \\
\text { receptor signaling pathways, regulates } \\
\text { proliferation of hematopoietic cells, regulates } \\
\text { differentiation of helper T cells (Th) to Th1 }\end{array}$ & $\begin{array}{l}\text { Advanced stage prostatic tumors, } \\
\text { schizophrenia, } \\
\text { hypertrophic cardiac diseases (animal } \\
\text { models) }\end{array}$ & None to date \\
\hline
\end{tabular}

Redox modifications have been reported for a subset of these proteins (e.g., EGFR, BTK, JAK3). 
A

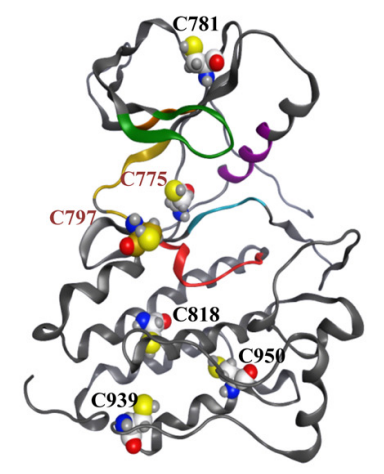

B

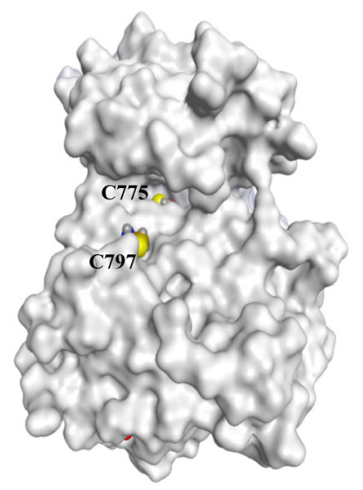

C

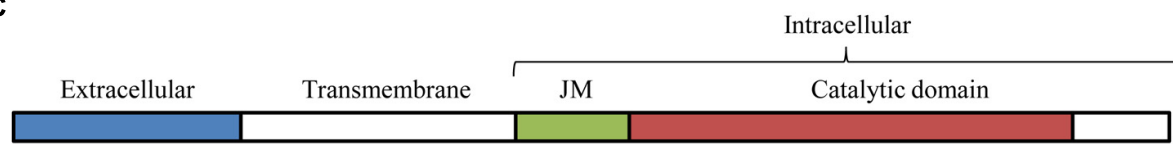

\begin{tabular}{|c|c|c|c|c|}
\hline Human & 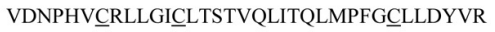 & LLNWC & PIÉTID & IMVKCWWIDAD \\
\hline Rhesus & 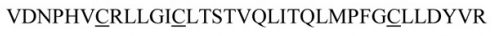 & LLNWÉVQIAKG & PICETID & IMVKCWWIDAD \\
\hline Chimpanzee & 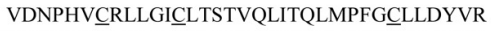 & LLNWĆVQIAKG & PIẸTID & IMVKCWWMIDAD \\
\hline Gorilla & VDNPHVㅁRLLGICLTSTVQLITQLMPFGㄷLLDYVR & LLNWC & PICETID & IMVKC \\
\hline Bovine & 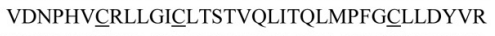 & LLNWC्VQIAKG & PIÉTID & IMVKCWMIDAD \\
\hline Pig & 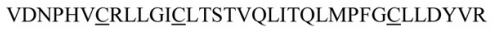 & LLNWC & PIÉTID & IMVKCWWIDAD \\
\hline Chicken & 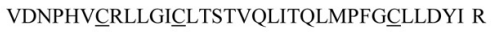 & LLNWĆVQIAKG & PICETID & IMVKC्WMIDAD \\
\hline Rat & 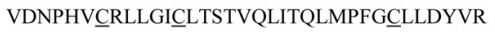 & LLNWĆVQIAKG & PIĆTID & IMVKCWMIDAD \\
\hline Mouse & 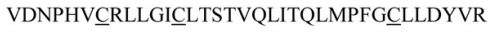 & LLNWC VQIAKG & PICETID & IMVKCWWMIDAD \\
\hline \multirow[t]{2}{*}{ Zebra fish } & VDNPHVㅁLLGICLLTSTVQLITQLMPFGㄷLLDYVR & LLNWC्VQIAKG & PIC̣TID & IMVK $\underline{C} W M I D A E$ \\
\hline & $\begin{array}{lll}\mathrm{C} 775 & \mathrm{C} 781 & \mathrm{C} 797\end{array}$ & C818 & C939 & C950 \\
\hline
\end{tabular}

D

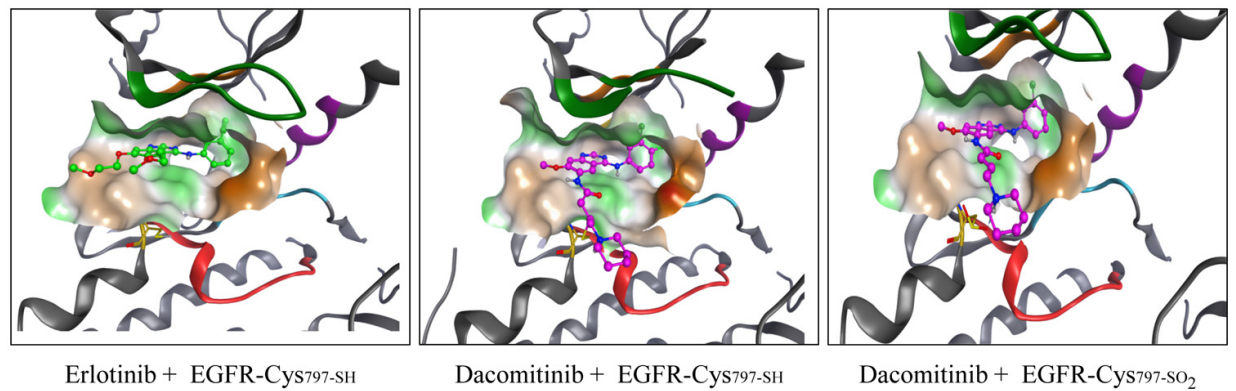

FIGURE 1 | Pharmacological role of evolutionarily conserved

EGFR-Cys 797 . (A) Catalytic domain of WT EGFR depicting all six cysteine residues. (B) Surface structure of WT EGFR shows Cys 775 and Cys 797 as the two solvent-accessible cysteine residues (PDB 1M14). (C) Schematic representation of EGFR domains: ligand binding extracellular domain (blue), the transmembrane domain (green), juxtamembrane region, JM (white) and the catalytic domain (red). Phylogenetic analysis of catalytic domain cysteine residues for the indicated species using the Uniprot Clustal O sequence alignment tool. Solvent-exposed cysteine residues are in red font. (D) Binding of small molecule inhibitors to the WT EGFR active site is shown in context of $\mathrm{Cys}_{797}$ (yellow; PDB 1M17). Reversible inhibitor erlotinib (green) binding to WT EGFR (left), covalent inhibitor dacomitinib (purple) binding to the reduced thiol Cys $797-S H$ of WT EGFR (middle) and the sulfinylated Cys ${ }_{797-S O 2}$ WT EGFR (right). are likely to undergo redox modifications. Historically, one of these solvent-exposed cysteines has been targeted for therapeutic intervention (Cys797).

Covalent kinase inhibition is a well-known pharmacological strategy that targets non-catalytic nucleophilic residues (e.g., Cys797 of EGFR) with electrophilic inhibitors. This approach was pursued to create highly potent drugs with prolonged pharmacological effects and enhanced selectivity (Singh et al., 1997; Schwartz et al., 2014). The most prevalent approach uses a Michael addition reaction of a nucleophilic cysteine thiol with the electron-deficient $\beta$-carbon of the Michael acceptor (MA) substituent of a covalent inhibitor. Several FDA-approved covalent drugs utilize this approach (e.g., afatinib, ibrutinib; Table 1). EGFR-Cys 797 is capable of undergoing multiple redox modifications (sulfinylation and glutathionylation) that can impact the potency of targeted drugs (Schwartz et al., 2014). Our studies show that reversible binding affinity of EGFR inhibitors is highly variable dependent on the inhibitor structure, the type of redox modification of Cys797, and 
the protein context (type of mutation). For example, biochemical affinity of the covalent inhibitor dacomitinib decreased by about 30-fold when the L858R EGFR mutant was glutathionylated $\left(K_{\mathrm{i}}\right.$ from 0.7 to $21 \mathrm{nM}$ ) but was unaffected by sulfinylation $\left(K_{\mathrm{i}}\right.$ from 0.7 to $1.0 \mathrm{nM})$. A similar trend was observed with the drugresistant L858R/T790M EGFR mutant, however, the loss in affinity was more substantial for the glutathionylated protein ( $>50$-fold). The active sites of WT and L858R mutant EGFR are structurally very similar, hence biochemical affinities of their covalent drugs are expected to be comparable. Modeling studies of dacomitinib interactions with WT EGFR and WT EGFR sulfinylated at $\mathrm{Cys}_{797}$ do not predict significant loss of interactions between the inhibitor MA and sulfinylated EGFR-Cys797 which is consistent with the modest decrease in affinities (Figure 1D). However, the more substantial loss of dacomitinib interactions with glutathionylated EGFR-Cys797 may occur due to reduced access of the inhibitor to the ATP-binding pocket therefore interfering with both covalent and non-covalent interactions. For non-covalent drugs such as erlotinib that do not require EGFR-Cys 797 interactions, the loss of affinity was modest for the both EGFR mutants (about twofold). As such, redox modifications of protein kinases can result in a wide range of pharmacological effects and be inhibitor-specific.

In cellular environments, the pharmacology of covalent inhibitors can be more complex due to spatially distinct and temporally controlled redox signaling mechanisms. The rate of formation and stability of oxidized-EGFR can vary depending on the local redox environment within subcellular compartments. Therefore, an inhibitor may have different interactions (i.e., potency) with a given protein based on its subcellular location. As such, two EGFR inhibitors may have a different spectrum of pharmacological effects due to their individual abilities to bind to different redox forms of EGFR. This new frontier of drug pharmacology should be exploited to create more effective and better-tolerated drugs.

\section{SUMMARY}

Despite their low abundance in the mammalian proteome, cysteine residues have emerged as important effectors of signaling regulation in both healthy cells and pathophysiological states. The chemistry of cysteine residues enables many types of post-translational oxidation reactions in cells with unique roles relative to the other amino acids. The conformational changes induced by redox modifications in signaling proteins can regulate biological outcomes. The spatial networks created by compartmentalized trafficking of redox-active proteins between distinct redox microenvironments impart selectivity to the kinase signaling. Temporal separation of the localized redox networks further refines signaling regulation. Specific cysteine oxidation events can also modulate small molecule inhibitor interactions and impact the clinical performance of these drugs. As such, redox analysis is necessary to gain a deeper understanding of biology and to design more effective drugs.

\section{AUTHOR CONTRIBUTIONS}

Both authors contributed to this work and approve the version to be published and are also accountable for all aspects of the work.

\section{ACKNOWLEDGMENTS}

We would like to acknowledge the Pfizer postdoctoral program for funding Revati Wani We would like to acknowledge the contribution of all the studies that allowed us to develop the concept in this manuscript, however, could not be cited owing to space limitations.

\section{REFERENCES}

Arteaga, C. L., and Engelman, J. A. (2014). ERBB receptors: from oncogene discovery to basic science to mechanism-Based cancer therapeutics. Cancer Cell 25, 282303. doi: 10.1016/j.ccr.2014.02.025

Bae, Y. S., Kang, S. W., Seo, M. S., Baines, I. C., Tekle, E., Chock, P. B., et al. (1997). Epidermal growth factor (EGF)-induced generation of hydrogen peroxide. Role in EGF receptor-mediated tyrosine phosphorylation. J. Biol. Chem. 272, 217-221. doi: 10.1074/jbc.272.1.217

Bindoli, A., Fukuto, J. M., and Forman, H. J. (2008). Thiol chemistry in peroxidase catalysis and redox signaling. Antioxid. Redox Signal. 10, 1549-1564. doi: 10.1089/ars.2008.2063

Bindoli, A., and Rigobello, M. P. (2013). Principles in redox signaling: from chemistry to functional significance. Antioxid. Redox Signal. 18, 1557-1593. doi: 10.1089/ars.2012.4655

Bourles, E., Isaac, M., Lebrun, C., Latour, J. M., and Seneque, O. (2011). Oxidation of $\mathrm{Zn}(\mathrm{Cys}) 4$ zinc finger peptides by $\mathrm{O}_{2}$ and $\mathrm{H}_{2} \mathrm{O}_{2}$ : products, mechanism and kinetics. Chemistry 17, 13762-13772. doi: 10.1002/chem.201101913

Brandes, N., Schmitt, S., and Jakob, U. (2009). Thiol-based redox switches in eukaryotic proteins. Antioxid. Redox Signal. 11, 997-1014. doi: 10.1089/ARS.200 8.2285

Carpenter, G., and Liao, H. J. (2009). Trafficking of receptor tyrosine kinases to the nucleus. Exp. Cell Res. 315, 1556-1566. doi: 10.1016/j.yexcr.2008.09.027

Chen, K., Kirber, M. T., Xiao, H., Yang, Y., and Keaney, J. F. Jr. (2008). Regulation of ROS signal transduction by NADPH oxidase 4 localization. J. Cell. Biol. 181, 1129-1139. doi: 10.1083/jcb.200709049

Chigaev, A., Zwartz, G. J., Buranda, T., Edwards, B. S., Prossnitz, E. R., and Sklar, L. A. (2004). Conformational regulation of alpha 4 beta 1-integrin affinity by reducing agents. "Inside-out" signaling is independent of and additive to reduction-regulated integrin activation. J. Biol. Chem. 279, 32435-32443. doi: 10.1074/jbc.M404387200

Corcoran, A., and Cotter, T. G. (2013). Redox regulation of protein kinases. FEBS J. 280, 1944-1965. doi: 10.1111/febs.12224

Cremers, C. M., and Jakob, U. (2013). Oxidant sensing by reversible disulfide bond formation. J. Biol. Chem. 288, 26489-26496. doi: 10.1074/jbc.R113.462929

Cross, J. V., and Templeton, D. J. (2006). Regulation of signal transduction through protein cysteine oxidation. Antioxid. Redox Signal. 8, 1819-1827. doi: 10.1089/ars.2006.8.1819

D'Autreaux, B., and Toledano, M. B. (2007). ROS as signalling molecules: mechanisms that generate specificity in ROS homeostasis. Nat. Rev. Mol. Cell Biol. 8, 813-824. doi: 10.1038/nrm2256

Diao, Y., Liu, W., Wong, C. C. L., Wang, X., Lee, K., Cheung, P.-Y., et al. (2010). Oxidation-induced intramolecular disulfide bond inactivates mitogen-activated protein kinase kinase 6 by inhibiting ATP binding. Proc. Natl. Acad. Sci. U.S.A. 107, 20974-20979. doi: 10.1073/pnas.1007225107

Dickinson, B. C., and Chang, C. J. (2011). Chemistry and biology of reactive oxygen species in signaling or stress responses. Nat. Chem. Biol. 7, 504-511. doi: $10.1038 /$ nchembio. 607

Drose, S., and Brandt, U. (2012). Molecular mechanisms of superoxide production by the mitochondrial respiratory chain. Adv. Exp. Med. Biol. 748, 145-169. doi: 10.1007/978-1-4614-3573-0_6

El Hajjaji, H., Dumoulin, M., Matagne, A., Colau, D., Roos, G., Messens, J., et al. (2009). The zinc center influences the redox and thermodynamic properties of Escherichia coli thioredoxin 2. J. Mol. Biol. 386, 60-71. doi: 10.1016/j.jmb.2008.11.046

Fan, S. W., George, R. A., Haworth, N. L., Feng, L. L., Liu, J. Y., and Wouters, M. A. (2009). Conformational changes in redox pairs of protein structures. Protein Sci. 18, 1745-1765. doi: 10.1002/pro.175

Farah, M. E., Sirotkin, V., Haarer, B., Kakhniashvili, D., and Amberg, D. C. (2011). Diverse protective roles of the actin cytoskeleton during oxidative stress. Cytoskeleton 68, 340-354. doi: 10.1002/cm.20516 
Foley, T. D., Petro, L. A., Stredny, C. M., and Coppa, T. M. (2007). Oxidative inhibition of protein phosphatase $2 \mathrm{~A}$ activity: role of catalytic subunit disulfides. Neurochem. Res. 32, 1957-1964. doi: 10.1007/s11064-007-9394-x

García-Yagüe, Á. J., Rada, P., Rojo, A. I., Lastres-Becker, I., and Cuadrado, A. (2013). Nuclear import and export signals control the subcellular localization of Nurr1 protein in response to oxidative stress. J. Biol. Chem. 288, 5506-5517. doi: 10.1074/jbc.M112.439190

Giannoni, E., Buricchi, F., Raugei, G., Ramponi, G., and Chiarugi, P. (2005). Intracellular reactive oxygen species activate Src tyrosine kinase during cell adhesion and anchorage-dependent cell growth. Mol. Cell. Biol. 25, 6391-6403. doi: $10.1128 / \mathrm{mcb} .25 .15 .6391-6403.2005$

Gopalakrishna, R., and Jaken, S. (2000). Protein kinase C signaling and oxidative stress. Free Radic. Biol. Med. 28, 1349-1361. doi: 10.1016/S0891-5849(00)0 0221-5

Heo, L., Cho, Y. B., Lee, M. S., Roe, J. H., and Seok, C. (2013). Alternative zincbinding sites explain the redox sensitivity of zinc-containing anti-sigma factors. Proteins 81, 1644-1652. doi: 10.1002/prot.24323

Ilbert, M., Graf, P. C., and Jakob, U. (2006). Zinc center as redox switch-new function for an old motif. Antioxid. Redox Signal. 8, 835-846. doi: 10.1089/ars.200 6.8.835

Jacob, C., Battaglia, E., Burkholz, T., Peng, D., Bagrel, D., and Montenarh, M. (2011). Control of oxidative posttranslational cysteine modifications: from intricate chemistry to widespread biological and medical applications. Chem. Res. Toxicol. 25, 588-604. doi: 10.1021/tx200342b

Khan, E. M., Heidinger, J. M., Levy, M., Lisanti, M. P., Ravid, T., and Goldkorn, T. (2006). Epidermal growth factor receptor exposed to oxidative stress undergoes Src- and caveolin-1-dependent perinuclear trafficking. J. Biol. Chem. 281, 1448614493. doi: 10.1074/jbc.M509332200

Kitagishi, Y., and Matsuda, S. (2013). Redox regulation of tumor suppressor PTEN in cancer and aging (Review). Int. J. Mol. Med. 31, 511-515. doi: 10.3892/ijmm.2013.1235

Korichneva, I. (2005). Redox regulation of cardiac protein kinase C. Exp. Clin. Cardiol. 10, 256-261.

Kwon, J., Lee, S.-R., Yang, K.-S., Ahn, Y., Kim, Y. J., Stadtman, E. R., et al. (2004) Reversible oxidation and inactivation of the tumor suppressor PTEN in cells stimulated with peptide growth factors. Proc. Natl. Acad. Sci. U.S.A. 101, 1641916424. doi: 10.1073/pnas.0407396101

Landino, L. M., Koumas, M. T., Mason, C. E., and Alston, J. A. (2007) Modification of tubulin cysteines by nitric oxide and nitroxyl donors alters tubulin polymerization activity†. Chem. Res. Toxicol. 20, 1693-1700. doi: $10.1021 /$ tx7001492

Layani-Bazar, A., Skornick, I., Berrebi, A., Pauker, M. H., Noy, E., Silberman, A., et al. (2014). Redox modulation of adjacent thiols in VLA-4 by AS101 converts myeloid leukemia cells from a drug-resistant to drug-sensitive state. Cancer Res. 74, 3092-3103. doi: 10.1158/0008-5472.CAN-13-2159

Lu, L., Sun, X., Liu, Y., Zhao, H., Zhao, S., and Yang, H. (2012). DJ-1 upregulates tyrosine hydroxylase gene expression by activating its transcriptional factor Nurr1 via the ERK1/2 pathway. Int. J. Biochem. Cell Biol. 44, 65-71. doi: 10.1016/j.biocel.2011.09.007

Marinho, H. S., Real, C., Cyrne, L., Soares, H., and Antunes, F. (2014). Hydrogen peroxide sensing, signaling and regulation of transcription factors. Redox Biol. 2 , 535-562. doi: 10.1016/j.redox.2014.02.006

Miseta, A., and Csutora, P. (2000). Relationship between the occurrence of cysteine in proteins and the complexity of organisms. Mol. Biol. Evol. 17, 1232-1239. doi: 10.1093/oxfordjournals.molbev.a026406

Moskovitz, J. (2005). Methionine sulfoxide reductases: ubiquitous enzymes involved in antioxidant defense, protein regulation, and prevention of aging-associated diseases. Biochim. Biophys. Acta 1703, 213-219. doi: 10.1016/j.bbapap. 2004 . 09.003

Moskovitz, J., Maiti, P., Lopes, D. H., Oien, D. B., Attar, A., Liu, T., et al. (2011). Induction of methionine-sulfoxide reductases protects neurons from amyloid beta-protein insults in vitro and in vivo. Biochemistry 50, 10687-10697. doi: 10.1021/bi201426b

Murphy, J. E., Padilla, B. E., Hasdemir, B., Cottrell, G. S., and Bunnett, N. W. (2009). Endosomes: a legitimate platform for the signaling train. Proc. Natl. Acad. Sci. U.S.A. 106, 17615-17622. doi: 10.1073/pnas.0906541106

Östman, A., Frijhoff, J., Sandin, Å., and Böhmer, F.-D. (2011). Regulation of protein tyrosine phosphatases by reversible oxidation. J. Biochem. 150, 345-356. doi: $10.1093 / \mathrm{jb} / \mathrm{mvr} 104$
Oteiza, P. I. (2012). Zinc and the modulation of redox homeostasis. Free Radic. Biol. Med. 53, 1748-1759. doi: 10.1016/j.freeradbiomed.2012.08.568

O-Uchi, J., Ryu, S. Y., Jhun, B. S., Hurst, S., and Sheu, S. S. (2014). Mitochondrial ion channels/transporters as sensors and regulators of cellular redox signaling. Antioxid. Redox Signal. 21, 987-1006. doi: 10.1089/ars.2013.5681

Paige Davis Volk, A., and Moreland, J. G. (2014). "Chapter thirteen-ROS-containing endosomal compartments: implications for signaling," in Methods in Enzymology, ed. P. M. Conn (Iowa, IA: Academic Press), 201-224.

Parsons, Z. D., and Gates, K. S. (2013). Thiol-dependent recovery of catalytic activity from oxidized protein tyrosine phosphatases. Biochemistry 52, 6412-6423. doi: $10.1021 /$ bi400451m

Paulsen, C. E., Truong, T. H., Garcia, F. J., Homann, A., Gupta, V., Leonard,S. E., et al. (2012). Peroxide-dependent sulfenylation of the EGFR catalytic site enhances kinase activity. Nat. Chem. Biol. 8, 57-64. doi: 10.1038/nchembio.736

Pizarro, G. O., and Ogut, O. (2009). Impact of actin glutathionylation on the actomyosin-S1 ATPase. Biochemistry 48, 7533-7538. doi: 10.1021/bi900669m

Rao, R., Xu, D., Thelen, J., and Miernyk, J. (2013). Circles within circles: crosstalk between protein Ser/Thr/Tyr-phosphorylation and Met oxidation. BMC Bioinformatics 14:S14. doi: 10.1186/1471-2105-14-S14-S14

Ringman, J. M., Fithian, A. T., Gylys, K., Cummings, J. L., Coppola, G., Elashoff, D., et al. (2012). Plasma methionine sulfoxide in persons with familial Alzheimer's disease mutations. Dement. Geriatr. Cogn. Disord. 33, 219-225. doi: $10.1159 / 000338546000338546$

Roos, G., Foloppe, N., and Messens, J. (2013). Understanding the pK(a) of redox cysteines: the key role of hydrogen bonding. Antioxid. Redox Signal. 18, 94-127. doi: 10.1089/ars.2012.4521

Sasaki, T., Hiroki, K., and Yamashita, Y. (2013). The role of epidermal growth factor receptor in cancer metastasis and microenvironment. Biomed. Res. Int. 2013, 546318. doi: 10.1155/2013/546318

Schoneich, C. (2005). Methionine oxidation by reactive oxygen species: reaction mechanisms and relevance to Alzheimer's disease. Biochim. Biophys. Acta 1703, 111-119. doi: 10.1016/j.bbapap.2004.09.009

Schoneich, C. (2011). Cysteine residues as catalysts for covalent peptide and protein modification: a role for thiyl radicals? Biochem. Soc. Trans. 39, 1254-1259. doi: 10.1042/bst0391254

Schwartz, P. A., Kuzmic, P., Solowiej, J., Bergqvist, S., Bolanos, B., Almaden, C., et al. (2014). Covalent EGFR inhibitor analysis reveals importance of reversible interactions to potency and mechanisms of drug resistance. Proc. Natl. Acad. Sci. U.S.A. 111, 173-178. doi: 10.1073/pnas.1313733111

Seshacharyulu, P., Ponnusamy, M. P., Haridas, D., Jain, M., Ganti, A. K., and Batra, S. K. (2012). Targeting the EGFR signaling pathway in cancer therapy. Expert Opin. Ther. Targets 16, 15-31. doi: 10.1517/14728222.2011.648617

Singh, J., Dobrusin, E. M., Fry, D. W., Haske, T., Whitty, A., and Mcnamara, D. J. (1997). Structure-based design of a potent, selective, and irreversible inhibitor of the catalytic domain of the erbB receptor subfamily of protein tyrosine kinases. J. Med. Chem. 40, 1130-1135. doi: 10.1021/jm960380s

Sorkin, A., and Goh, L. K. (2009). Endocytosis and intracellular trafficking of ErbBs. Exp. Cell Res. 315, 683-696. doi: 10.1016/j.yexcr.2008.07.029

Steinberg, S. F. (2013). Oxidative stress and sarcomeric proteins. Circ. Res. 112, 393-405. doi: 10.1161/circresaha.111.300496

Surh, Y. J., Kundu, J. K., Na, H. K., and Lee, J. S. (2005). Redox-sensitive transcription factors as prime targets for chemoprevention with anti-inflammatory and antioxidative phytochemicals. J. Nutr. 135, 2993S-3001S.

Tomas, A., Futter, C. E., and Eden, E. R. (2014). EGF receptor trafficking: consequences for signaling and cancer. Trends Cell Biol. 24, 26-34. doi: 10.1016/j.tcb.2013.11.002

Wang, Y., Yang, J., and Yi, J. (2012). Redox sensing by proteins: oxidative modifications on cysteines and the consequent events. Antioxid. Redox Signal. 16, 649-657. doi: 10.1089/ars.2011.4313

Wani, R., Qian, J., Yin, L., Bechtold, E., King, S. B., Poole, L. B., et al. (2011). Isoformspecific regulation of Akt by PDGF-induced reactive oxygen species. Proc. Natl. Acad. Sci. U.S.A. 108, 10550-10555. doi: 10.1073/pnas.1011665108

Winterbourn, C. C. (2008). Reconciling the chemistry and biology of reactive oxygen species. Nat. Chem. Biol. 4, 278-286. doi: 10.1038/nchembio.85

Wouters, M. A., Fan, S. W., and Haworth, N. L. (2010). Disulfides as redox switches: from molecular mechanisms to functional significance. Antioxid. Redox Signal. 12, 53-91. doi: 10.1089/ARS.2009.2510

Yan, B., and Smith, J. W. (2000). A redox site involved in integrin activation. J. Biol. Chem. 275, 39964-39972. doi: 10.1074/jbc.M007041200 
Yan, B., and Smith, J. W. (2001). Mechanism of integrin activation by disulfide bond reduction. Biochemistry 40, 8861-8867. doi: 10.1021/bi002902i

Zhao, F., Ilbert, M., Varadan, R., Cremers, C. M., Hoyos, B., Acin-Perez, R., et al. (2011). Are zinc-finger domains of protein kinase $C$ dynamic structures that unfold by lipid or redox activation? Antioxid. Redox Signal. 14, 757-766. doi: 10.1089/ars.2010.3773

Zhong, X., and Wright, J. F. (2013). Biological insights into therapeutic protein modifications throughout trafficking and their biopharmaceutical applications. Int. J. Cell. Biol. 2013:273086. doi: 10.1155/2013/273086

Conflict of Interest Statement: The authors declare that the research was conducted in the absence of any commercial or financial relationships that could be construed as a potential conflict of interest.
Received: 08 July 2014; accepted: 17 September 2014; published online: 06 October 2014.

Citation: Wani R, Nagata A and Murray BW (2014) Protein redox chemistry: post-translational cysteine modifications that regulate signal transduction and drug pharmacology. Front. Pharmacol. 5:224. doi: 10.3389/fphar.2014.00224

This article was submitted to Pharmacology of Anti-Cancer Drugs, a section of the journal Frontiers in Pharmacology.

Copyright $(5) 2014$ Wani, Nagata and Murray. This is an open-access article distributed under the terms of the Creative Commons Attribution License (CC BY). The use, distribution or reproduction in other forums is permitted, provided the original author(s) or licensor are credited and that the original publication in this journal is cited, in accordance with accepted academic practice. No use, distribution or reproduction is permitted which does not comply with these terms. 